mIGROSGOPY TOPRY

JUกE \ด97

ISSUE \#97-5

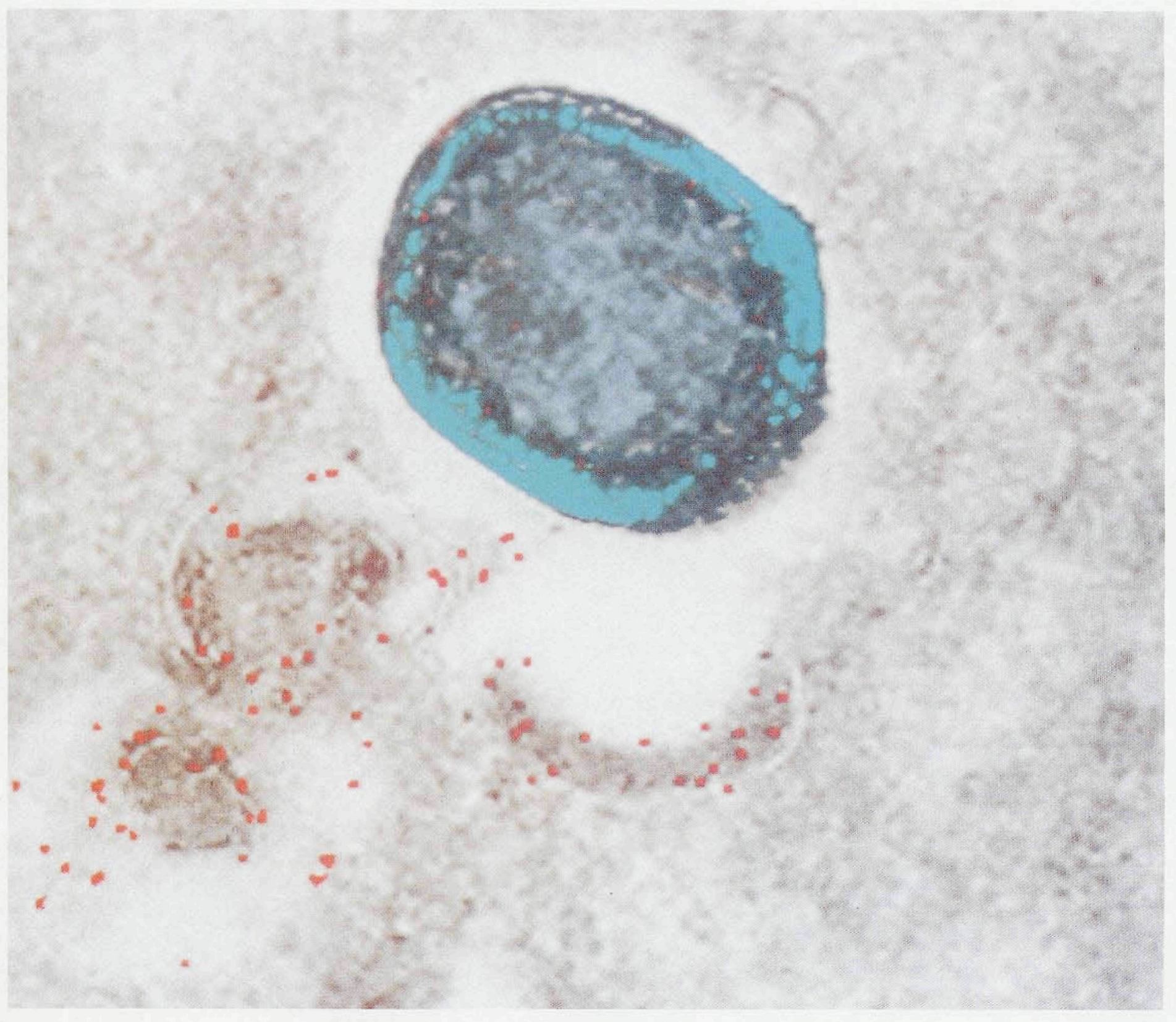


Rat skin muscle fabric -

in it's original - hydrated - form.

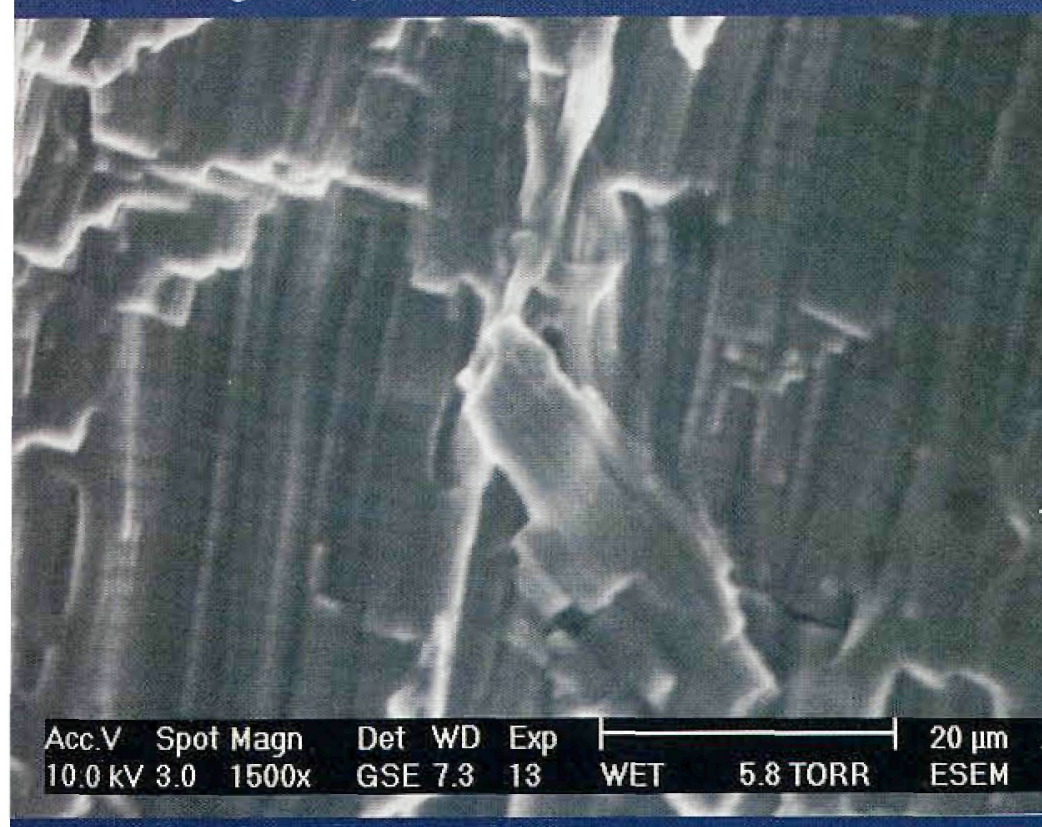

The

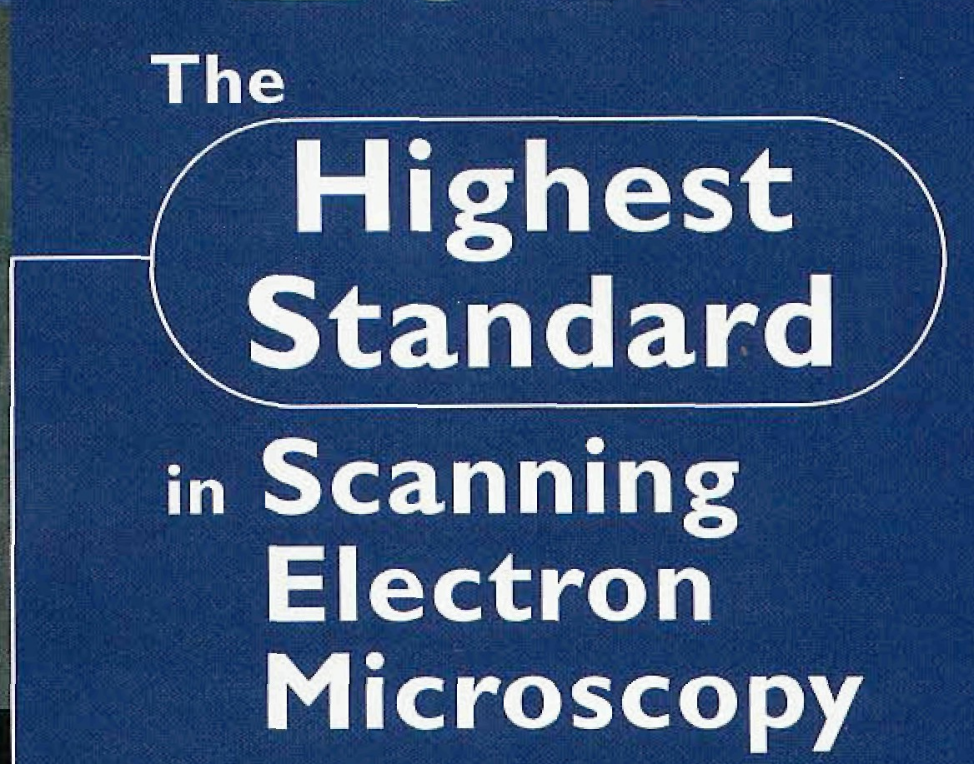

When ElectroScan developed its ESEM" technology in the mid-eighties it set new high standards in investigative scanning electron microscopy. A programme of continuous improvement, meanwhile, raised these standards even higher. So much so, that ElectroScan's patented ESEM technology is still the acknowledged industry benchmark, both for our competitors... and ourselves.

The exceptional imaging capabilities of ESEM" technology are not restricted to hydrated specimen observation and such like. An ESEM instrument can be configured in price and performance to suit a very much wider range of applications. Even a basic ESEM configuration is superior to any other SEM on the market.

So if you are looking for the highest standard in scanning electron microscopy, take a good look at a Philips-ElectroScan ESEM". We can offer you the "ultimate SEM" that, in application, price and performance, simply has no comparison.
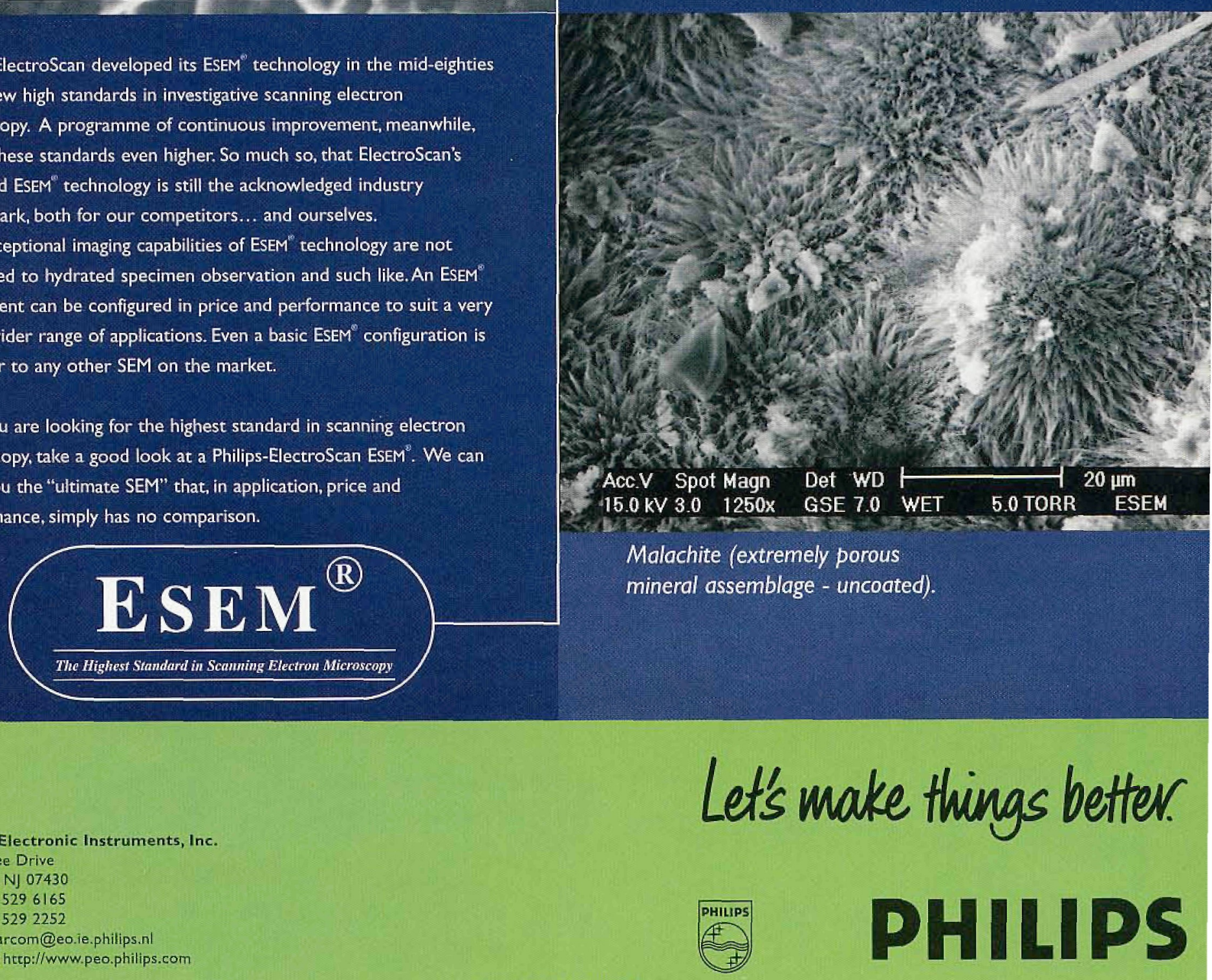


\section{MICROSCOPE MUSEUM}

Stephen W. Carmichael, ${ }^{1}$ Mayo Clinic

Recently, I had a delightfully pleasant surprise. I was attending a Human Embryology Conference in Washington, D.C., held at the National Museum of Health and Medicine, a Division of the Armed Forces Institute of Pathology. I've heard of the AFIP many times, but I had never been there, didn't even know where it was located. AFIP is located on the campus of Walter Reed Army Medical Center, which is bordered by Georgia Avenue. If you're driving, it's near the Maryland state line. If you're taking the Metro, get off at the Silver Springs stop and take a taxi.

Why am I directing you, a microscopist, to the AFIP? Within the AFIP is the National Museum of Health and Medicine, and within that very interesting museum is the Billings Microscope Collection. The museum and the collection are well worth a visit.

Lieutenant Colonel John S. Billings was Curator of the Army Medical Museum from 1883 to 1893 and is credited with establishing this world-class collection of microscopes. In 1865, Billings became the Librarian for the Surgeon General's Library, now the National Library of Medicine. He developed and published "Index Medicus," the first monthly index of medical periodicals, which has evolved into Grateful Med. The Surgeon General's Library was founded in 1836 . Through the efforts of Colonel Billings and his successors at the Museum, the microscope collection includes over 650 instruments, including microscopes used by Robert Hooke, Robert Koch, Rudolph Virchow, Walter Reed, and the instrument made especially for the 1901 Antarctic Expedition of Robert Scott. Also included in the collection are approximately 300 microscope accessories, over 150 microtomes, and approximately 10,000 slides made by Joseph $\mathrm{J}$. Woodward. Most of the instruments in the Collection are authentic, with a few reproductions of early 17 th century microscopes included for the sake of completeness. This includes a replica of a simple microscope made in about 1675 by Antoni van Leewenhoek, that looks just like the design presented by Alan Shinn in this publication. $^{2}$ The Leewenhoek replica was made circa 1890 by Robert Mayall, the person who sold the nucleus of the collection to Billings.

The march of science and technology can be followed as you walk along the collection. Perhaps even more interesting is the artistic flair of the instrument makers, particularly seen in the earlier microscopes. The craftsmanship is absolutely astonishing! There are subtle and interesting improvements that can be noticed, including the focusing mechanisms, the stability and utility of the base, the mirrors or prisms for bringing light to the specimen, etc. Improvements in the lenses, including some of the early achromatic lenses to be manufactured, is more difficult to appreciate. But they're there. One can visualize improvements in the optical microscopes right up to the beginning of this century. From that point on, the emphasis seems to be in the manufacturing of the microscopes, with little in the way of improvements to the instruments themselves.

As you might expect, as you reach the end of the collection there are electron microscopes on display. I must admit that it was more than a little disconcerting to see a RCA-3F on display. This was the model with which I did my dissertation research. Did this make me feel old! But the history of unrelenting progress is there for all to see, and this made me feel a part of it.

The Historical Collections Manager at the National Museum of Health and Medicine is Alan Hawk. If you have a request to see a specific instrument, or class of instruments, that are not on display, you may contact him in advance at hawk@email.afip.osd.mil and arrange to see items of interest when you visit. The museum is open every day except Christmas, 10am to $5: 30 \mathrm{pm}$

1. The author gratefully acknowledges Alan Hawk, Historical Collections Manager for the National Museum of Health and Medicine, for reviewing this article.

2. Shinn, A., To Make a Leewenhoek Microscope Replica, Microscopy Today, 96-6:14, 1996

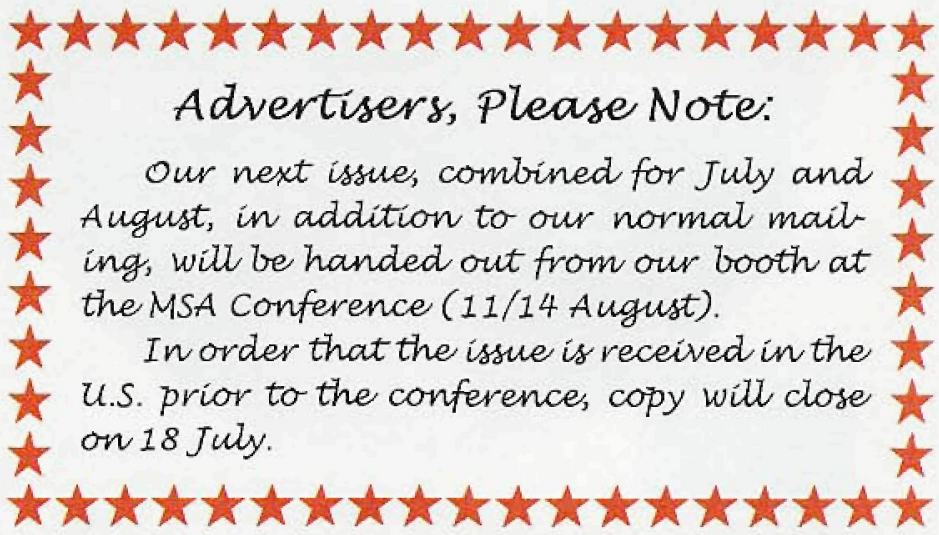

\section{Front Page Image}

\section{Colorized Cryosection Labeled With Colloidal Gold}

Micrograph of a thawed cryosection through a Listeria monocytogenes-infected macrophage. The infected cell was loaded with 3-(2,4-dinitroanilino)-3'-amino- $\mathrm{N}$-methyldipropylamine (DAMP), which accumulates in subcellular organelles with low $\mathrm{pH}$. The intracellular DAMP was detected using specific antibodies and protein A-gold probes (seen in red). Low $\mathrm{pH}$-containing compartments are seen fusing with the phagosome in which is contained a $\mathrm{L}$. monocytogenes bacterium (in green).

Image provided curtesy of Paul Webster, Yale School of Medicine, Center for Cell Imaging.

For further information on this process, refer to Dr. Webster's article on page 12 of this issue.

\section{mICROSCOPY TODAY}

A monthly newsletter dedicated to the unique interests in microscopy and mailed to some 8,000 microscopists worldwide - at no cost in the U.S. and with a modest international charge:

PO Box 620122, Middleton, WI 53562 - Tel.: (608)836-1970 - Fax: (608)836-1969) - Mail: MicroToday@aol.com

http://www.microscopy-today.com

Copyright in 1997 by Today Enterprises. All rights reserved.

Don Grimes, Editor 